\title{
Thoracic Fluid
}

National Cancer Institute

\section{Source}

National Cancer Institute. Thoracic Fluid. NCI Thesaurus. Code C125897.

Fluid that is present in the thoracic cavity. 